\title{
A Study of the Corrosion Inhibition of Mild Steel in 0.5M Tetraoxosulphate (VI) acid by Alstonia boonei Leaves Extract as an Inhibitor at Different Temperatures.
}

\author{
Evelyn.U.Godwin-Nwakwasi ${ }^{1}$, Elachi.E.Elachi ${ }^{2}$, Mercy.A.Ezeokonkwo ${ }^{3}$, \\ Lawrence.E.Onwuchuruba ${ }^{4}$ \\ ${ }^{1}$ Department of Chemistry, Gregory University, Uturu, Abia State, Nigeria. \\ Email: ${ }^{2}$ Department of Mechanical Engineering, Gregory University, Uturu, Abia State, Nigeria. \\ ${ }^{3}$ Department of Pure and Industrial Chemistry, University of Nigeria, Nnsuka, Enugu State, Nigeria. \\ ${ }^{4}$ Department of Chemistry, Imo State University, Owerri, Imo State, Nigeria.
}

\begin{abstract}
A comparative study of the corrosion inhibition performance of Alstonia boonei leaves extract in $0.5 \mathrm{M}$ tetraoxosulphate (VI) acid at different temperatures $\left(30^{\circ} \mathrm{C}\right.$, $50^{\circ} \mathrm{C}$ and $70^{\circ} \mathrm{C}$ ) was undertaken. The results showed that Alstonia boonei leaves extract was more efficient as a corrosion inhibitor at $30^{\circ} \mathrm{C}$ compared to temperatures of $50^{\circ} \mathrm{C}$ and $70^{\circ} \mathrm{C}$.The adsorption of Alstonia boonei leaves extract was found to obey Langmuir adsorption isotherm at all temperatures $\left(30^{\circ} \mathrm{C}, 50^{\circ} \mathrm{C}\right.$ and $\left.70^{\circ} \mathrm{C}\right)$, but did not obey Freundlich adsorption isotherm at all temperatures. A study of the effect of temperature on corrosion rate and inhibition efficiency showed that corrosion rate increased with increase in temperature, while the inhibition efficiency decreased with increase in temperature.
\end{abstract}

Keywords - Adsorption, Corrosion, Efficiency, Inhibition, Isotherm.

\section{INTRODUCTION}

One of the commonest methods of mitigating the corrosion of metals and alloys in corrosive environments is by the use of inhibitors. A corrosion inhibitor is a substance which when added in small concentrations to an environment, effectively reduces the corrosion rate of the metal exposed to that environment [1]. Corrosion inhibitors are commonly added in small concentrations to acids, cooling water, steam and other environments; either continuously or intermittently to reduce corrosion. Corrosion inhibitors reduce the rate of corrosion by adsorption of ion molecules onto the metal surface, increasing or decreasing the anodic and/or cathodic reaction, decreasing the diffusion rate for reactants to the surface of the metal and decreasing the electrical resistance of the metal surface [2]. Chemical based corrosion inhibitors have been successfully used to control the corrosion of metals and alloys in various media [3-5]. However, due to the high toxic nature of chemical based corrosion inhibitors [6], there is need to develop environmentally acceptable and inexpensive green corrosion inhibitors. Green corrosion inhibitors are cheap, ecologically friendly and possess no threat to the environment [7]. There are numerous reports on the use of extracts from plants to control the corrosion of mild steel in several media. The leaves of Nyctanthes arbortristis acted as good corrosion inhibitor for mild steel in tetraoxosulphate (VI) acid medium [8]. The inhibition efficiency increased with increase in the concentration of the extract and maximum inhibition efficiency of $90 \%$ was obtained at inhibitor concentration of $1 \% \mathrm{v} / \mathrm{v}$. Extract of Citrus aurantiifolia was found to be effective in $1 \mathrm{M}$ hydrochloric acid with efficiency of up to $97.51 \%$ [9]. Ethanol extract of Andrographis paniculata inhibited the corrosion of mild steel in hydrochloric acid solution through the mechanism of physical adsorption [10]. Alcoholic extracts of eight plants (Lycium shawii, Teucrium oliverianum, Ochradenus baccatus, Anvillea garcinii, Cassia italica, Artemisia sieberi, Carthamus tinctorius and Tripleurospermum auriculatum) inhibited the corrosion of mild steel in acidic media through adsorption and acted as mixed type inhibitors [11]. Aqueous extracts of damsissa lupine and half - bar retarded the partial cathodic reaction of the corrosion of 7075 - T6 aluminium alloy in aqueous solution of $0.5 \mathrm{M}$ sodium chloride [12]. Lupine extract had 
the highest inhibition efficiency while half - bar extract had the lowest inhibition efficiency.

The inhibitive action of plant extracts could be attributed to the presence of phytochemical constituents present in the extracts [11-14]. Most of these phytochemical constituents have complicated molecular structures, large molecular weights and significant number of oxygen, sulphur and nitrogen atoms incorporated in their structures [11-14]. These compounds can adsorb on the metal surface via the lone pairs of electrons present in their oxygen, sulphur and nitrogen atoms [11-15]. The adsorption of such compounds decreases the surface area of contact with the corrodent, thereby reducing the corrosion of the metal. Extract of Uncaria gambir could serve as an effective corrosion inhibitor of mild steel in aqueous solution [16]. Electrochemical studies showed that the corrosion inhibition of mild steel in aqueous solution of Uncaria gambir extract was highest at a concentration of $150 \mathrm{ppm}$ in solution with a pH of 5 [16].

Though, numerous plants have been studied and proven to possess corrosion inhibition potentials, there are still many that have not been studied for their anticorrosion potentials [11]. In order to increase the number of plants that possess anticorrosion potentials, we report the corrosion inhibition potentials of Alstonia boonei leaves extract. To the best of our knowledge, Alstonia boonei has not been studied for its corrosion inhibition properties, therefore the need to undertake the study. Phytochemical analyses of ethanoic extract of Alstonia boonei revealed the presence of the following phytochemical compounds: saponins, general glycosides, flavonoids, terpenoids and steroids, carotenoids, coumarins, alkaloids, anthraquinones and glycosides [17]. These phytochemical constituents are mostly responsible for the corrosion inhibition of plants [11-14]; therefore Alstonia boonei has anticorrosion potentials. In line with this, it became necessary to compare the corrosion inhibition performance of Alstonia boonei leaves extract at various temperatures $\left(30^{\circ} \mathrm{C}, 50^{\circ} \mathrm{C}\right.$ and $\left.70^{\circ} \mathrm{C}\right)$. Secondly, to study the effect of temperature on the corrosion of mild steel in tetraoxosulphate (VI) acid medium using Alstonia boonei leaves extract as an inhibitor. This will be accomplished using Arrhenius and Eyring's equations.

Chemical reaction kinetics is the study of the rates of chemical processes [18]. It includes investigations of how different experimental conditions can influence the rate of a chemical reaction and yields information about the reaction mechanism, as well as the construction of mathematical models that can describe the characteristics of chemical reaction [19]

\section{METHOD}

2.1 Materials and Equipment

The materials used for the study were: mild steel sheet, Alstonia boonei leaves, absolute ethanol, $0.5 \mathrm{M}$ tetraoxosulphate (VI) acid and distilled water. Equipment used were: Electronic balance, electric oven, stopwatch, beakers, abrasive papers and reflux condenser.

2.2 Preparation of corrosion test specimen

Mild steel sheet was mechanically press cut to produce corrosion test specimens each of dimensions $30 \mathrm{~mm} \times 15$ $\mathrm{mm} \times 1.2 \mathrm{~mm}$. A $3 \mathrm{~mm}$ diameter hole was drilled on each specimen to facilitate easy suspension and withdrawal from the corrodent.The surfaces of the test specimens were polished with abrasive papers to produce smooth surfaces. For surface treatment, the test specimens were decreased in absolute ethanol, washed in distilled water. The washed specimens were cleaned with cotton wool and oven dried .The dried specimens were weighed to obtain the initial weights and stored in a desiccator.

2.3 Preparation of plant extract

The leaves of Alstonia boonei were obtained from Uramuuruwa Onuga forest in Umude Avuvu, Ikeduru, Imo State, Nigeria. The leaves were identified in the Department of Plant Science and Biotechnology, Imo State University, Owerri, Nigeria. The leaves were shade dried for two weeks .The leaves were grounded into powdery form and stored in airtight containers. A stock solution of the plant extract was obtained by refluxing 25 grammes of the powdered Alstonia boonei leaves in $500 \mathrm{~mL}$ of $0.5 \mathrm{M}$ tetraoxosulphate (VI) acid for three hours. The refluxed solution was filtered to remove any contaminant which might be present. The required concentrations of the extract $(2.5 \mathrm{~g} / \mathrm{L}, 5.0 \mathrm{~g} / \mathrm{L}, 10.0$ $\mathrm{g} / \mathrm{L}, 25 \mathrm{~g} / \mathrm{L}$ and $50 \mathrm{~g} / \mathrm{L}$ ) needed for corrosion studies were prepared from the stock solution.

\subsection{Experimental}

The weight loss measurements were carried out as previously described by [20]. However, weight loss measurements were conducted at temperatures of $30^{\circ} \mathrm{C}$, $50^{\circ} \mathrm{C}$ and $70^{\circ} \mathrm{C}$ respectively. The mild steel specimens were each suspended and totally immersed in $0.5 \mathrm{M}$ tetraoxosulphate (VI) acid without and with different concentrations $(2.5 \mathrm{~g} / \mathrm{L}, 5.0 \mathrm{~g} / \mathrm{L}, 10 \mathrm{~g} / \mathrm{L}, 25 \mathrm{~g} / \mathrm{L}$ and $50 \mathrm{~g} / \mathrm{L})$ with the aid of strings and rods for ten hours, washed thoroughly in ethanol, rinsed in distilled water, dried and weighed to obtain the final weight. The weight loss was obtained by computing the difference between the initial weight and final weight .From the weight loss results, the corrosion rate was computed using equation (1) [7]:

Corrosion rate $(\mathrm{mm} / \mathrm{yr})=\frac{87.6 \mathrm{~W}}{\rho A t} \ldots . .(1)$ 
Where $\mathrm{W}$ is the weight loss in grammes, $\rho$ is the density of the specimen in $\mathrm{gcm}^{-3}, \mathrm{~A}$ is the area of the specimen in $\mathrm{cm}^{2}$ and $\mathrm{t}$ is the exposure time in hours. The inhibition efficiency (I \%) of Alstonia boonei leaves extract was computed using equation (2) [7] :

$$
\mathrm{I} \%=\left(1-\frac{W i}{W o}\right) \times 100 \ldots .
$$

$\mathrm{W}_{\mathrm{i}}=$ weight loss in the presence of inhibitor

$\mathrm{W}_{\mathrm{o}}=$ weight loss in the absence of inhibitor

\section{RESULTS AND DISCUSSION}

3.1 Comparison of the corrosion inhibition performance of the extract at different temperatures.

This is undertaken with a view to establish the temperature at which Alstonia boonei leaves extract will function optimally as a corrosion inhibitor in $0.5 \mathrm{M}$ tetraoxosulphate (VI) acid medium. Presented in Fig.1 are the calculated values of corrosion rates

$(\mathrm{mm} / \mathrm{yr})$ of mild steel in $0.5 \mathrm{M}$ tetraoxosulphate(VI) acid in the presence of Alstonia boonei leaves extract at temperatures of $30^{\circ} \mathrm{C}, 50^{\circ} \mathrm{C}$ and $70^{\circ} \mathrm{C}$. The corrosion rate decreased as the concentration of the extract increased from $0.25 \mathrm{~g} / \mathrm{L}$ to $50 \mathrm{~g} / \mathrm{L}$. A comparison of the corrosion rates at $30^{\circ} \mathrm{C}, 50^{\circ} \mathrm{C}$ and $70^{\circ} \mathrm{C}$ revealed that the corrosion rates obtained at $30^{\circ} \mathrm{C}$ were lower compared to the corrosion rates at temperatures of $50^{\circ} \mathrm{C}$ and $70^{\circ} \mathrm{C}$. Maximum values of corrosion rates were obtained at temperature of $70^{\circ} \mathrm{C}$. Also presented in Fig. 2 are the calculated values of inhibition efficiency (I \%) of

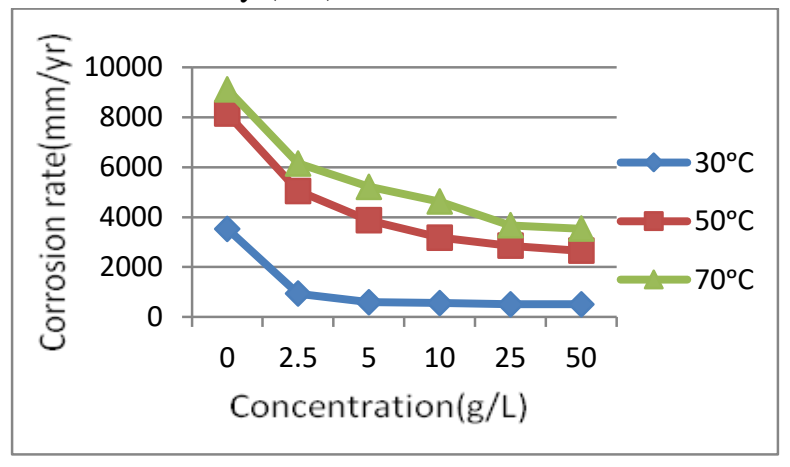

Fig. 1: Variation of corrosion rate with temperature

Alstonia boonei leaves extract at temperatures of $30^{\circ} \mathrm{C}, 50^{\circ} \mathrm{C}$ and $70^{\circ} \mathrm{C}$. The inhibition efficiency increased with increase in the concentration of Alstonia boonei leaves extract, probably due to an increase in the surface area covered by the extract [7].

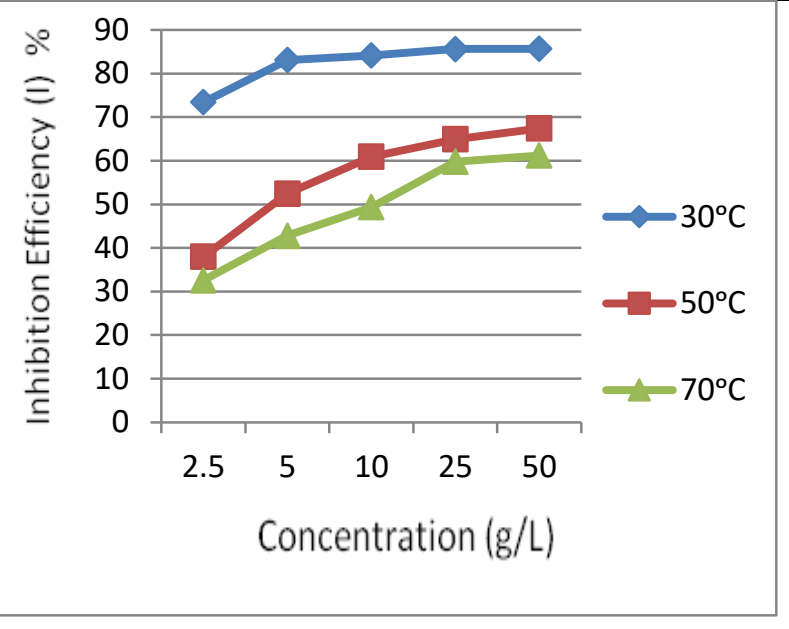

Fig. 2: Variation of inhibition efficiency with concentration

A comparison of the inhibition efficiencies obtained at different temperatures $\left(30^{\circ} \mathrm{C}, 50^{\circ} \mathrm{C}\right.$ and $\left.70^{\circ} \mathrm{C}\right)$ showed that the extract was more efficient as an inhibitor at low temperature $\left(30^{\circ} \mathrm{C}\right)$ compared to temperatures of $50^{\circ} \mathrm{C}$ and $70^{\circ} \mathrm{C}$. The high inhibition performance of the extract at low temperature $\left(30^{\circ} \mathrm{C}\right)$ could be due to the fact that as the temperature increases, there is weakening of the inhibitor film on the metal surface [21]. Therefore, a greater area of the metal surface is available for corrosion reaction at high temperature(s).

\subsection{Adsorption isotherm}

The adsorption process of organic inhibitor molecules occurs due to the replacement of water molecules adsorbed on metallic surface as represented by equation (3):

Org ${ }_{(\text {sol })}+\mathrm{xH}_{2} \mathrm{O} \rightarrow \mathrm{Org}_{\text {(ads) }}+\mathrm{H}_{2} \mathrm{O} \ldots$... (3)

Where $\mathrm{x}$ is the number of $\mathrm{H}_{2} \mathrm{O}$ molecules replaced by one organic molecule.

The degree of surface coverage $(\Theta)$ obtained from the weight loss measurements were used to evaluate the isotherm that best fits the data. The degree of surface coverage $(\Theta)$ was computed using equation (4) [7]:

$$
\Theta=1-\frac{W i}{W o} \text {. }
$$

Where $\mathrm{W}_{\mathrm{i}}$ and $\mathrm{W}_{\mathrm{o}}$ are the weight losses in the presence and absence of the inhibitor respectively. Values of linear correlation coefficients obtained from the plots were used to determine the isotherm most applicable to the experimental data [21].

The Langmuir adsorption isotherm model is based on the assumption that the adsorption takes place at specific homogeneous sites within the adsorbent [14]. The Langmuir adsorption isotherm model is represented by equation (5) $[14,22]:$

$$
\frac{\text { Cinh }}{\theta}=\frac{1}{\text { Kads }}+\mathrm{C}_{\mathrm{inh}} \ldots \ldots .
$$


Where $\mathrm{K}_{\mathrm{ads}}\left(\mathrm{Lg}^{-1}\right)$ is the adsorption equilibrium constant and $\mathrm{C}_{\mathrm{inh}}$ is the inhibitor concentration. Fig .3 shows the Langmuir adsorption isotherm plots for the adsorption of Alstonia boonei leaves extract at temperatures of $30^{\circ} \mathrm{C}$, $50^{\circ} \mathrm{C}$, and $70^{\circ} \mathrm{C}$. Straight lines were obtained with $\mathrm{R}^{2}$ close to unity at each temperature. This is an indication that the adsorption of the extracts at temperatures of $30^{\circ} \mathrm{C}, 50^{\circ} \mathrm{C}$ and $70^{\circ} \mathrm{C}$ obeyed Langmuir adsorption isotherm [23]. It also indicates that Alstonia boonei extract species occupies typical adsorption sites at the metal /solution interface [24]. The values of the Langmuir

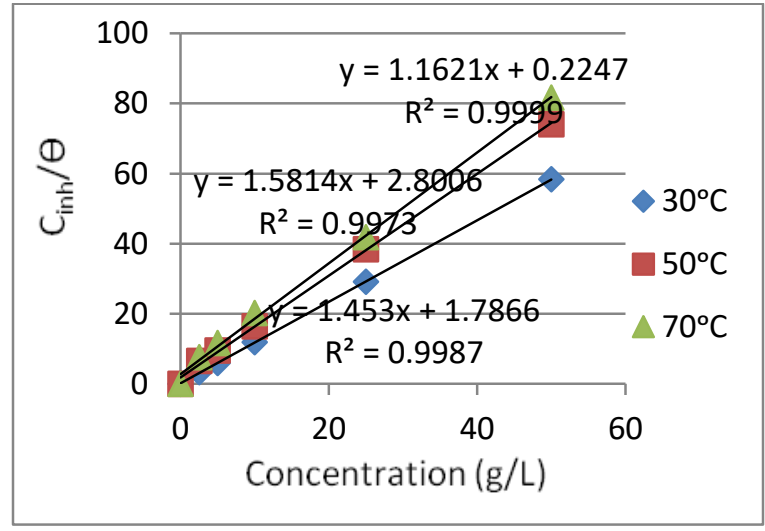

Fig. 3: Langmuir adsorption isotherm plots for the corrosion of mild steel in $0.5 \mathrm{M} \mathrm{H}_{2} \mathrm{SO}_{4}$ in the presence of the extract at different temperatures.

Table 1: Langmuir adsorption isotherm parameters for the corrosion of mild steel in $\mathrm{H} 2 \mathrm{SO} 4$ in the presence of the

\begin{tabular}{lccc}
\multicolumn{4}{c}{ extract. } \\
\hline Temp $\left({ }^{\circ} \mathrm{C}\right) \mathrm{K}(\mathrm{ads})$ & $\Delta \mathrm{G}_{\text {ads }}^{\mathrm{o}}(\mathrm{KJ} / \mathrm{mol})$ & $\mathrm{R}^{2}$ \\
\hline 30 & 4.46 & -21.17 & 0.999 \\
50 & 0.56 & -17.00 & 0.998 \\
70 & 0.36 & -16.79 & 0.997
\end{tabular}

Adsorption isotherm parameters obtained from the plots are presented in TABLE 1. The adsorption equilibrium constant $\left(\mathrm{K}_{\mathrm{ads}}\right)$ decreased with increase in temperature from $30^{\circ} \mathrm{C}$ to $70^{\circ} \mathrm{C}$. Since the efficiency of an inhibitor is a function of the magnitude of the adsorption constant $\left(\mathrm{K}_{\mathrm{ads}}\right)$, large values of $\mathrm{K}_{\mathrm{ads}}$ is an indication of better and stronger interaction between the inhibitor molecules and the metal, whereas small values of $\mathrm{K}_{\mathrm{ads}}$ mean weak interaction [25]. The value of the adsorption equilibrium constant $\left(\mathrm{K}_{\mathrm{ads}}\right)$ obtained at $30^{\circ} \mathrm{C}$ is higher compared to the values obtained at $50^{\circ} \mathrm{C}$ and $70^{\circ} \mathrm{C}$. This implies that Alstonia boonei leaves extract was more efficient as an inhibitor at $30^{\circ} \mathrm{C}$ compared to the other temperatures $\left(50^{\circ} \mathrm{C}\right.$ and $\left.70^{\circ} \mathrm{C}\right)$.

The Freundlich isotherm is mostly used for heterogeneous surface energy systems (non-uniform distribution of sorption heat) [26]. The Freundlich adsorption isotherm is defined by equation (6) [27]:

$\log \Theta=\log K_{a d s}+n \log [C](0<n<1) \ldots$ (6)

Fig. 4 shows the Freundlich adsorption isotherm plots for the adsorption of Alstonia boonei extract at temperatures of $30^{\circ} \mathrm{C}, 50^{\circ} \mathrm{C}$ and $70^{\circ} \mathrm{C}$. Straight lines were obtained with $\mathrm{R}^{2}$ values presented in TABLE 2. The values of $n$ and $K_{a d s}$ were evaluated from the slopes and intercepts of the plots [27]. These values are presented in TABLE 2. The adsorption equilibrium constant $\left(\mathrm{K}_{\mathrm{ads}}\right)$ decreases as the temperature increased from $30^{\circ} \mathrm{C}$ to $70^{\circ} \mathrm{C}$. The highest value of $\mathrm{K}_{\mathrm{ads}}$ was obtained at a temperature of $30^{\circ} \mathrm{C}$ which is to further confirm that Alstonia boonei extract was more efficient at $30^{\circ} \mathrm{C}$ compared to temperatures of $50^{\circ} \mathrm{C}$ and $70^{\circ} \mathrm{C}$. The $\mathrm{n}$ values lie between 0 and 1 at all temperatures which signifies strong bond between the extract and metal surface [28]. However, the $\mathrm{R}^{2}$ values obtained were not close to unity, therefore poor fit was obtained with Freundlich isotherm.

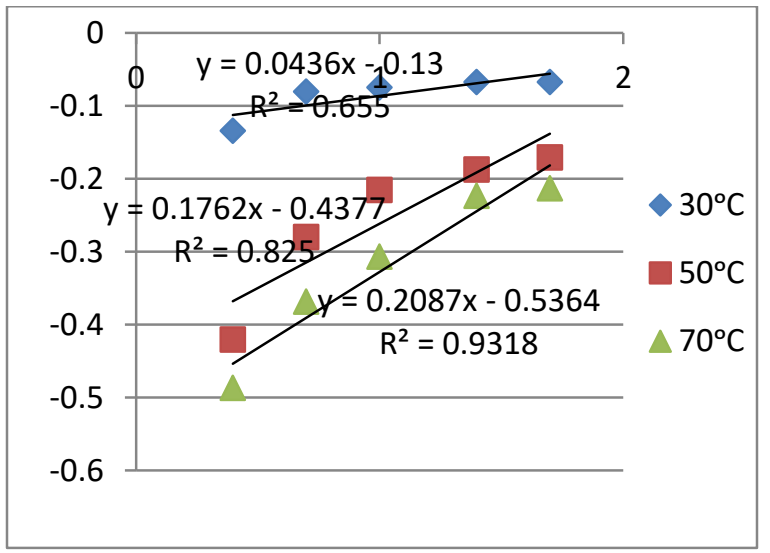

Fig. 4: Freundlich adsorption isotherm plots for the corrosion of mild steel in the presence of Alstonia boonei extract.

Table 2: Freunlich adsorption isotherm parameters for the adsorption of Alstonia boonei leaves extract on the metal surface.

\begin{tabular}{|c|c|c|c|c|}
\hline \multicolumn{2}{|c|}{ Temp $\left({ }^{\circ} \mathrm{C}\right) \mathrm{K}_{\mathrm{ads}}$} & $\mathrm{n}$ & \multicolumn{2}{|c|}{$\Delta \mathrm{G}^{\text {ads }}(\mathrm{KJ} / \mathrm{mol}) \quad \mathrm{R}^{2}$} \\
\hline 30 & 0.741 & 0.043 & -16.65 & 0.655 \\
\hline 50 & 0.366 & 0.176 & -27 & 0.825 \\
\hline 70 & 0.291 & 0.208 & -16.18 & 0.931 \\
\hline
\end{tabular}

The adsorption equilibrium constant $\left(\mathrm{K}_{\mathrm{ads}}\right)$ is related to the free energy of adsorption ( $\left.\Delta \mathrm{G}_{\text {ads }}\right)$ by equation (6) [14]:

$$
\log \mathrm{K}_{\mathrm{ads}}=-\log \mathrm{C}_{\mathrm{H} 2 \mathrm{O}}-\frac{\Delta \text { Gads }}{2.303 R T} \ldots
$$

Where $C_{H 2 O}$ is the concentration of water in solution expressed in $\mathrm{g} / \mathrm{L}, \mathrm{R}$ is the universal gas constant, $\mathrm{T}$ is the absolute temperature. The free energy of adsorption $\left(\Delta \mathrm{G}_{\mathrm{ads}}\right)$ obtained using equation (6) are presented in TABLES 1 and 
2. The results are negative in all cases which imply that the adsorption of Alstonia boonei extract on the metal surface is a spontaneous process $[7,15]$. Values of $\Delta \mathrm{G}_{\mathrm{ads}}$ up to -20 $\mathrm{KJ} / \mathrm{mol}$ are consistent with electrostatic interaction between charged inhibitor molecules and a charged metal (physical adsorption) [7, 23]. Therefore Alstonia boonei leaves extract inhibit the corrosion process by physically adsorbing onto the metal surface.

3.3 Effect of temperature.

The effect of temperature on corrosion rate and inhibition efficiency are presented in Figs. 4 and 5 respectively. The corrosion rate increased with increase in temperature and the inhibition efficiency decreased with increase in temperature. This could be attributed to the fact that at high temperatures, the desorption of the Alstonia boonei extract occurs and causes mild steel to be exposed to the corrodent [21].

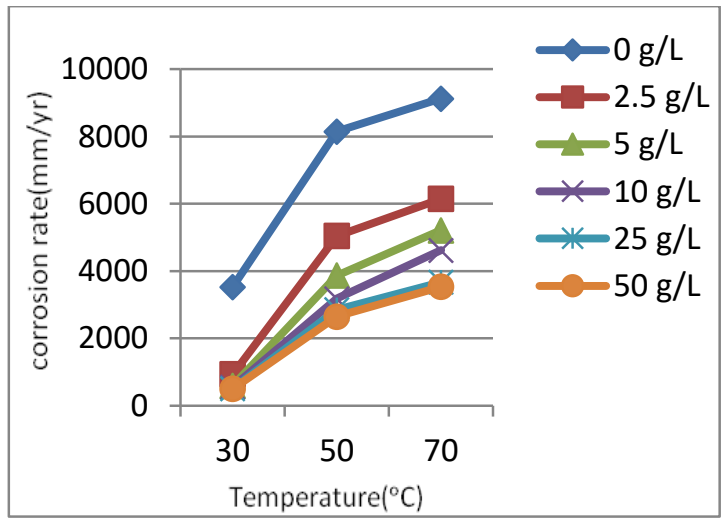

Fig. 4: Effect of temperature on corrosion rate

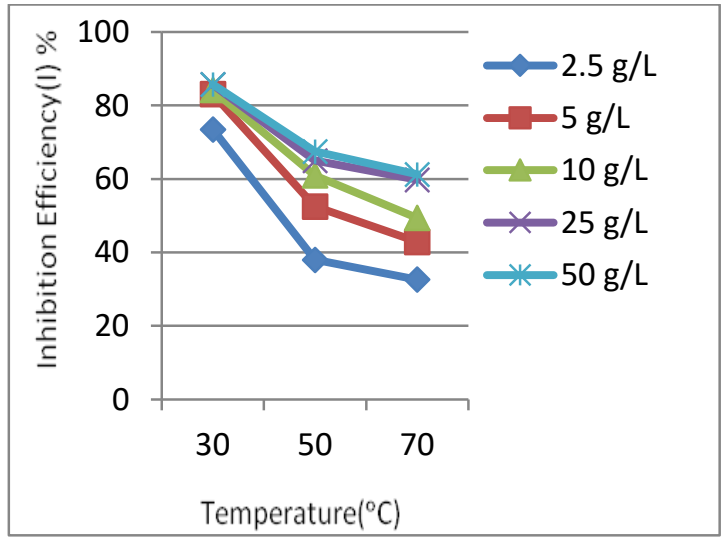

Fig 5: Effect of temperature on inhibition efficiency.

Consequently, massive deterioration of the specimen occured at elevated temperatures.

The apparent activation energy ( $\mathrm{E}_{\mathrm{app}}$ ) for the corrosion of mild steel in $0.5 \mathrm{M} \mathrm{H}_{2} \mathrm{SO}_{4}$ is computed using Arrhenius equation in (7) [15]:

$$
\log \mathrm{CR}=\log \mathrm{A}-\frac{E a p p}{2.303 R T} \ldots
$$

Where CR is the corrosion rate, $\mathrm{R}$ is the gas constant and $\mathrm{T}$ is the absolute temperature. Fig.5 represents the plot of LogCR versus $1 / \mathrm{T}$ for the corrosion of mild steel in $0.5 \mathrm{M}$ $\mathrm{H}_{2} \mathrm{SO}_{4}$ in the absence and presence of various concentrations of Alstonia boonei extract. Straight lines were obtained. The values of the apparent activation energy $\left(E_{\text {app }}\right)$ were obtained from the slopes of the plots $[7,15]$ and are presented in TABLE 3. The values of the apparent energy of activation $\left(\mathrm{E}_{\mathrm{app}}\right)$ in the presence of various concentration of Alstonia boonei leaves extract were higher compared solution to the value obtained in the blank $(0.0$ g/L). Similar results were also gotten by $[7,15]$. This could be attributed to the desorption of the inhibitor molecules (Alstonia boonei leaves extract) which occurs on the surface of the metal as temperature increases [21]. The increase in activation energy in the presence of the extract signifies physical adsorption $[7,21]$

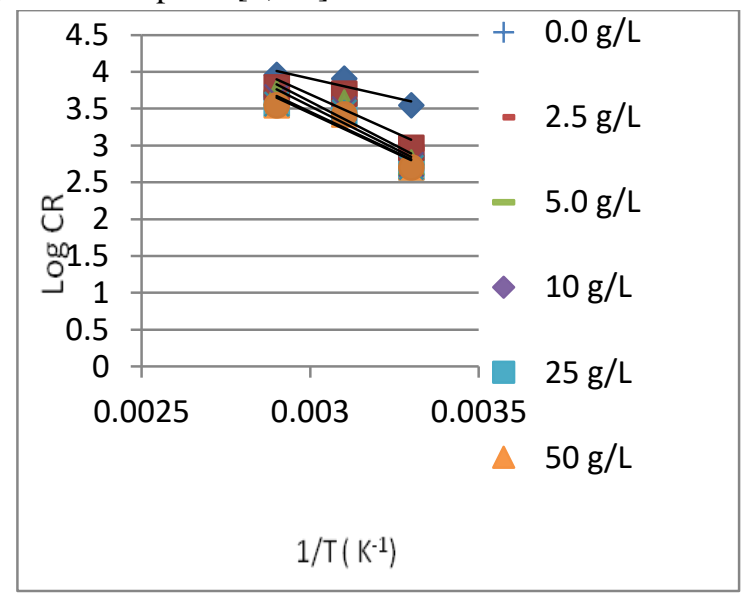

Fig. 5: Arrhenius plots for the corrosion of mild steel in $0.5 \mathrm{M} \mathrm{H}_{2} \mathrm{SO}_{4}$ without and with different concentrations of extract.

Table.3: Activation energy parameters for the corrosion of mild steel in $0.5 \mathrm{M} \mathrm{H}_{2} \mathrm{SO}_{4}$ in the presence and absence of Alstonia boonei extract

\begin{tabular}{lc}
\hline Concentration $(\mathrm{g} / \mathrm{L})$ & $\mathrm{E}_{\mathrm{app}}(\mathrm{KJ} / \mathrm{mol})$ \\
\hline 0 & 19.74 \\
2.5 & 39.10 \\
5.0 & 45.09 \\
10 & 43.92 \\
25 & 41.15 \\
50 & 40.44 \\
\hline
\end{tabular}

The enthalpy of activation $\left(\Delta \mathrm{H}^{\ddagger}\right)$ and the entropy of activation $\left(\Delta \mathrm{S}^{\neq}\right)$were computed using Eyring's equation given in (8) [27]

$-\operatorname{In} \frac{R h}{N t} \operatorname{Rc}=\frac{\Delta H^{\ddagger}}{R T}-\frac{\Delta S^{\neq}}{R} \ldots \ldots . .8$ 
Where $\mathrm{h}$ is the Plank's constant, $\mathrm{N}$ is the Avogadro's number, $\mathrm{T}$ is the absolute temperature, $\mathrm{R}$ is the gas constant, $\mathrm{R}_{\mathrm{c}}$ is the corrosion rate.

Presented in Fig. 6 is the plot of $-\operatorname{In} \frac{h R c}{K_{B T}} \operatorname{versus} \frac{1}{T} . \mathrm{K}_{\mathrm{B}}$ is Boltzmann constant and equals the term $\frac{R}{N}$ [27]. Straight lines were obtained. The activation parameters obtained from the slopes and intercepts [27] are presented in TABLE 4

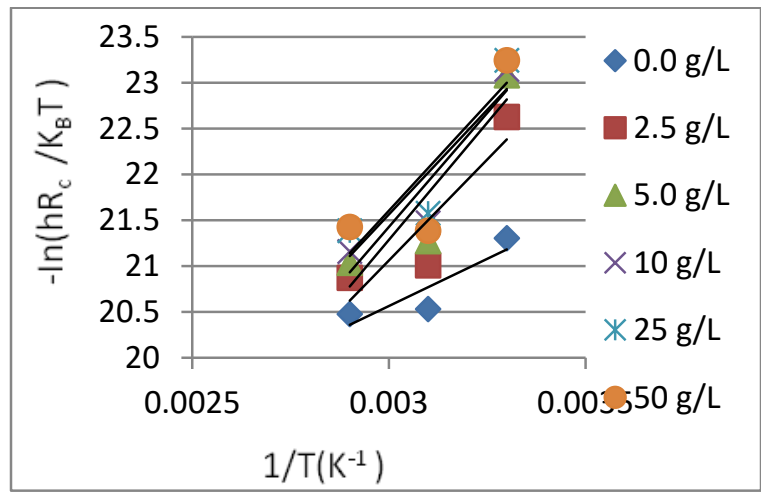

Fig 6: Eyrings plot for the corrosion of mild steel in 0.5M $\mathrm{H}_{2} \mathrm{SO}_{4}$ in the absence and presence of the extract.

The enthalpy of activation $\left(\Delta \mathrm{H}^{\ddagger}\right)$ in the presence of various concentrations of the extract was higher compared to the value obtained in the absence of the extract. This implies that the energy barrier of corrosion reaction increases with the concentration of the extract and activated complex can be formed faster in the blank solution [28, 29].

The positive values of $\Delta \mathrm{H}^{\ddagger}$ is an indication that the adsorption of the extract on the metal surface is an endothermic process [28].The negative values of $\Delta \mathrm{S}^{\neq}$in the presence and absence of the inhibitor is an indication that the activated complex in the rate determining step represents an association rather than a dissociation step [29].This implies that there is more disorderliness in the solution without any extract [29].

Table 4: Activation parameters for the corrosion of mild steel in $0.5 \mathrm{M} \mathrm{H}_{2} \mathrm{SO}_{4}$ in the absence and presence of the

\begin{tabular}{lcc}
\multicolumn{3}{c}{ extract } \\
\hline Conc. $(\mathrm{g} / \mathrm{L})$ & $\Delta \mathrm{H}^{\ddagger}(\mathrm{KJ} / \mathrm{mol})$ & $\Delta \mathrm{S}^{\ddagger}(\mathrm{J} / \mathrm{mol})$ \\
\hline 0 & 17.16 & -119.47 \\
2.5 & 36.52 & -65.58 \\
5.0 & 42.51 & -49.44 \\
10 & 41.35 & -54.12 \\
25 & 38.57 & -63.92 \\
50 & 37.86 & -65.71 \\
\hline
\end{tabular}

\section{CONCLUSION}

Based on the experimental results obtained, Alstonia boonei leaves extract inhibited the corrosion of mild steel in tetraoxosulphate (VI) acid. Therefore, plant materials could replace synthetic chemicals as inhibitors. They are cheaper, readily available, renewable sources of materials, environmentally friendly and ecologically acceptable. The use of extracts from plants to control corrosion will lead to a reduction in maintenance cost. This is because the incessant breakdown of equipment will be greatly reduced, thereby reducing the frequency of replacing broken down equipment.

\section{REFERENCES}

[1] Patni, N., Agarwal, S., Shah, P (2013).Greener approach towards corrosion.Chinese Journal of Engineering (ISSN: 2314-8063(E)/10 pages (O)), 2013, doi.org/10.1155/2013/784186.

[2] Amitha, B. A., Basu B. J (2012). Green inhibitors for corrosion protection of metals and alloys. International Journal of Corrosion (ISSN: 1687-9333(E)/11pages (O)), 2012,doi:10.1155/2012/380217.

[3] Amuda, M.O.H., Soremekun, A.O.O., Oladoye, A (2008). Improving the corrosion inhibitive strength of sodium sulphite in hydrogen cyanide solution using sodium benzoate. Leonard Electronic Journal of Particles and Technologies (ISSN: 1583- 1078(E)/75 63(O)), 13.

[4] Loto, R.T., Loto, C.A., Popoola, P.A (2014). Corrosion inhibition of 2- amino - 5 ethyl - 1, 3, 4 thiadiazole on mild steel in hydrochloric acid. Canadian Journal of Pure and Applied Sciences (ISSN: 1920 -3853(E)/3103 -3091(O)), 8(3).

[5] Guzman, M., Lara, R., Vera, L (2009). 5 - amino 1, 3, 4 - thiadiazole -2 - thiol corrosion current density and adsorption thermodynamics on ASTM A 890 - 1B stainless steel in a $3.5 \% \mathrm{NaCl}$ solution. Journal of the Chilean Chemical Society (ISSN: 0717 - 9707(E)/18 - 1(O)), 549(2), doi: 10.4067/S0717 97072009000200005 .

[6] Ezemonye, L.I.N., Ogeleka, D.F., Okeimen, F.E (2006). Toxicity of negate (industrial detergent) and norust cr 486(corrosion inhibitors) to earthworms (Aporrectodea longa) in naturally spiked soil. African Journal of Biotechnology (ISSN: $1684-5315(\mathrm{E}) / 1117$ - 1113(O)), 5(11), doi: 10.5897/AJB.

[7] Umoren, S. A., Obot, I.B., Ebenso, E.E., Okafor, P.C (2008). Eco - friendly inhibitors from naturally occurring exudates gums for aluminium corrosion inhibition in acidic medium. Portugaliae 
Electrochemical Acta (ISSN: 1647 - 1571(E)/282 267(O)), 26.

[8] Sartha, R., Vasudha, V.G (2009). Inhibition of mild steel corrosion in $1 \mathrm{~N}$ tetraoxosulphate (VI) acid medium by acid extract of Nyctanthes arbortristis leaves. Electronic Journal of Chemistry (ISSN: 2090 9071(E)/1008 - $10003(\mathrm{O})), \quad 6(4)$, doi:org/10.1155/2009/694607.

[9] Saratha, R., Priya, S.V., Thilagavathy,P (2009).Investigation of Citrus aurantiifolia leaves extract as corrosion inhibitor for mild steel in $1 \mathrm{M}$ hydrochloric acid. Electronic Journal of Chemistry (ISSN: 2090 - 9071(E)/795 - 785(O)), 6(3), doi:org/10.1155/2009/107807

[10] Eddy, N.O., Awe,F.E., Asiaka,A.A., Magaji, L., Ebenso, E.E (2011).Chemical information from GC MS studies of ethanol extract of Andrographis paniculata and their corrosion inhibition potentials on mild steel in $\mathrm{HCl}$ solution. International Journal of Electrochemical Science (ISSN: 1452 - 3981/4328 4316), 6.

[11] Al - Otaibi, M.S., Al - Mayouf, A.M., Khan, M., Mousa, A.A., Al - Mazroa, S.A., Alkhathlan, H.Z (2012). Corrosion inhibitory action of some plant extracts on the corrosion of mild steel in acidic media. Arabian Journal of Chemistry (ISSN: $1878-5352 / 346$ - 340(O)), 2014(7), http://dx.doi.org/10.1016/j.arabjc.2012.01.015

[12] Fetouh, H.A., Abdel - Fattah, T.M., El - Tantawy, M.S (2014). Novel plant extracts as green corrosion inhibitors for 7075 - T6 aluminium alloy in an aqueous medium. International Journal of Electrochemical Science (ISSN: 1452 - 3981/1582 1565(O)), 9 .

[13] Okafor, P.C., Ebenso, E.E., Ekpe, U.J (2010). Azadirachta indica extracts as corrosion inhibitor for mild steel in acid medium. International Journal of Electrochemical Science (ISSN: 1452 - 3981/993 978(O)), 5 .

[14]Eddy, N. O. (2009). Inhibitive and adsorption properties of ethanol extract of Colocasia esculenta leaves for the corrosion of mild steel in $\mathrm{H}_{2} \mathrm{SO}_{4}$. International Journal of Physical Sciences (ISSN 1992 - 1950/171 - 165(O)), 4(4), doi: 10.5897/IJPS.

[15]Noor, E.A (2009). Potential aqueous extract of Hibiscus sabdariffa leaves for inhibiting the corrosion of aluminium in alkaline solutions. Journal of Applied Electrochemistry (ISSN: 1572- 8838(E)/1475 1465(O)), 39, doi: 10.1007/s10800 - 009 - 9826 -1.
[16]Hussin, M.H., Kassim M.J (2010). Electrochemical studies of mild steel corrosion inhibition in aqueous solution by Uncaria gambir extract. Journal of Physical Sciences (ISSN: $2180-4230(\mathrm{E}) / 13-1(\mathrm{O})$ ), 2(1).

[17] Opoku, F., Akoto, O (2015). Antimicrobial and phytochemical properties of Alstonia boonei extracts.Organic Chemistry Current Research (ISSN: $2161-0401 / 4-1(\mathrm{O})), \quad 4(1)$, http://dx.doi/10.4172/2161 - 0401.1000137.

[18] Khadom, A.A., Yaro, A.S., Kadum, A.A.H., Altaie, A.S., Musa, A.Y (2009). The effect of temperature and acid concentration on corrosion of low carbon steel in hydrochloric acid media. American Journal of Applied Sciences (ISSN 1546 - 9239/1409 - 1403(O)), 6(7).

[19] Undiandeye, J.A., Chior, T.J., Mohammed, A., Offurum, J.C (2014). Kinetics of the corrosion of mild steel in petroleum- water mixture using ethy ester of lard as inhibitor. African Journal of Pure and Applied Chemistry (ISSN: $1996-0840 / 67-60(\mathrm{O})$ ), 8(3): doi: 10.5897/AJPC 2013.0491.

[20]Elachi E.E, Tuleun L.T, Ashwe A (2016). Comparative study of corrosion inhibition performance of two plant extracts in cassava fluid. Umudike Journal of Engineering and Technology (ISSN: 2536 - 7404(P)/70 - 61(O)), 2(2).

[21] Al - Amiery, A.A., Kadhum, A.A.H., Kadihum, A., Mohamad, A., How, C.K., Junaedi, S (2014). Inhibition of mild steel corrosion in sulphuric acid solution new schiff base. Materials (ISSN: $1996-$ 1944(E)/804 - 787(O)), 7, doi: 10.3390/ma7020787

[22] Lgaz, H., Salghi, R., Larouj, M., Elfaydy, M., Jodeh, S., Rouifi, Z., Lakhrissi, Oudda, B. (2016). Experimental, Theoritical and Monte Carlo simulation of quinoline derivative as effective corrosion inhibitor for mild steel in $1 \mathrm{M} \mathrm{HCl}$. Journal of Materials and Environmental Science(ISSN:2028 - 2508(E)/4488 4471(O)).

[23] Chaubey, N., Yadav, D. K., Singh, V. K., Quraishi, M.A."A comparative study of leaves extract for corrosion inhibition effect on aluminium alloy in alkaline medium", Ain Shams Eng. J. in press.

[24]Erhayem, M., Al - Tohami, F., Mohammed, R., Ahmida, K. (2015). Isotherm, Kinetic and thermodynamic studies for the sorption of mercury (II) onto activated carbon from Rosmarinus officinalis leaves. American Journal of AnalyticalChemistry( ISSN:2156 - 8278/10-1), http.dx.doi.org/10.4236/ajac.2015.61001. 
[25]EL - Awady, A., Abd - Nabey, B. A., Aziz, S. G.(1993). Thermodynamic and kinetic factors in chloride ion pitting and nitrogen donor ligands inhibition of aluminium metal corrosion in aggressive acid media. Journal of the Chemical Society; Faraday Transactions (ISSN: 0956 - 5000/802 - 795), 89, doi: 10.1039/FT9938900795.

[26] Atar, N., Olgun, A., Wang, S. (2012).Adsorption of Cadmium (II) and Zinc (II) on boron enrichment process waste in aqueous solutions: batch and fixed bed systems studies. Chemical Engineering Journal (ISSN: $\quad(1385-8947 / 7-1), \quad 192$, http://dx.doi.org/10.1016/j.cej.2012.03.067

[27]Hassan, R. M., Zaafarany, I. A. (2013).Kinetics of corrosion inhibition of aluminium in acidic media by water - soluble natural polymeric pectates as anionic polyelectrolyte inhibitors. Materials (ISSN: $1996-$ 1944(E)/2451-2436(O)), 6, doi: 10.3390/ma6062436.

[28]Elwady, G.Y., El - Said, I. A., Fouda, A.S. (2008). Anion surfactants as corrosion inhibitors for aluminium dissolution in $\mathrm{HCl}$ solutions. International Journal of Electrochemical Science (ISSN: 1452 3981/190 - 177(O)), 3(2008).

[29] Undiandeye J.A, Okewale A O, Etuk B. R Igbokwe P.K (2011).Investigation of the use of ethyl esters of castor seed oil and rubber seed oil as corrosion inhibitors. International Journal of Basic and Applied Sciences (ISSN: 2227 - 5053/48 - 54(O)), 11(6). 